\title{
Economic Model for FTTH Access Network Design
}

\author{
Z. Havic ${ }^{1, *}$, B. Mikac ${ }^{2}$ \\ ${ }^{1} \mathrm{BH}$ Telecom Sarajevo, Bosnia and Herzegovina \\ ${ }^{2}$ Faculty of Electrical Engineering and Computing, University of Zagreb, Croatia
}

Copyright $(\mathcal{C} 2015$ by authors, all rights reserved. Authors agree that this article remains permanently open access under the terms of the Creative Commons Attribution License 4.0 International License

\begin{abstract}
Many telecom operators nowadays are gradually increasing their bandwidth offers, by either shortening the copper lengths to the user (e.g. to introduce VDSL) or by reducing the shared service areas for HFC (e.g. to adopt DOCSIS 2.0/3.0). This policy brings the fibre closer to the user, and it is one of the strategies taken by $\mathrm{BH}$ Telecom Sarajevo. However, there is an intention to perform the switchover to FTTH. In the paper are evaluated rollout scenarios for FTTH in Bosnia \& Herzegovina in rural, suburban and urban area. The intention is to determine the general feasibility of a nationwide FTTH rollout in Bosnia \& Herzegovina together with a thorough comparison between the different areas. In addition an analysis and estimation are presented showing the influence and importance of parameters in the final evaluation of an FTTH rollout. Model proposed one can use in other countries, taking into account specific local conditions. In all analyses cost evaluation is carried out.
\end{abstract}

Keywords FTTH, Cost Model, Optical Network, Sensitivity

\section{Introduction}

The focus of this study is on the evaluation of a Fibre to the Home (FTTH) fixed access network deployment in Bosnia \& Herzegovina. This merges knowledge of technological background with an economic evaluation methodology. The study provides a detailed overview and introduction to both.

Currently, telecom operators are adapting their networks for triple-play services that offer Internet, IP Television (IPTV) and Voice-over-IP (VoIP) services distributed over the same network. Such network leads to increase in bandwidth demand. The current DSL and HFC technologies will run out of bandwidth. Optical fibre based access networks can deliver a future-proof solution for interactive multimedia applications.

FTTx is a future-proof solution that is definitely able to reduce the capacity bottleneck in the access network. But
FTTx network suffers from its installation cost, mainly dominated by digging or trenching costs. Solutions and analysis of installation costs one can find at many of authors [1], [2], [23]. The authors have evaluated several rollout scenarios for Fibre To the Home (FTTH) by considering a so-called evolutionary and revolutionary approach towards FTTH performed for GPON architecture. They have determined the feasibility of a nationwide FTTH rollout in their countries. We will evaluate and analyse two rollout scenarios for Bosnia \& Herzegovina; Point to Point (P2P) and Point to Multipoint (P2MP).

\section{Cost Model}

In currently existing FTTH deployments we can distinguish two architectures with major differences, passive and active optical networks.

In a passive optical network (PON), a customer is connected to the equipment by means of a point-to-multipoint fibre network. An optical $(1: N)$ splitter will power-split the signal from one source into $N$ equal signals towards destinations. In opposite direction the splitter will couple the incoming signals from $N$ sources into one signal directed to one destination. The splitters are installed between the $C O$ and the customer. The resulting tree structure couples several customers to one fibre and one equipment port in the $C O$. The bandwidth of this fibre is shared among the different customers. Time division multiplexing (TDM) protocols are used to share the medium. Each customer receives a time window during which it is allowed to send and receive data over the shared network.

In an active optical network ( $A O N)$, the customer is connected to the equipment by means of a dedicated fibre. There are no intermediate splitters and the bandwidth is not shared among different customers. Depending on where the active equipment is located, we make a further distinction between home run network (HRN) and active star network $(A S N)$ topology. In an HRN the fibre runs all the way to the $C O$ while in an ASN, the active equipment is placed much closer to the customer and an active street cabinet (SC) will serve a comparable number of customers as in a traditional 
PON (32-256 customers per $S C$ ).

Since there are no optical splitters, the optical budget is only constrained by the attenuation and splice- and connector losses. In this case, even low optical budgets will still allow for very high distances between customer and $C O$.

Cost function $\operatorname{cost}(t)$ is defined [1] :

$$
\cos t(t)=\sum_{t} \sum_{j=0}^{C}\left[\frac{d_{c}(t)}{g_{c}}\right] \cdot p_{c}(t)
$$

with:

$c$ - no. of equipment types or trenches to install

$d_{c}$ - the required amount of $c$ type of equipment installed in time $t$ (years)

$g_{c}$ - the granularity of $c$ type of equipment, e.g. km fibre-cable wound on a reel, number of ports per OLT-card (Optical Line Termination) $p_{c}$ - the price of $c$ equipment at the given granularity

We can split the cost function:

cost $_{C O}$ - the equipment price in $C O$ (central office) depending on optical port number,

cost $_{L}$ - trench price between $C O$ and customer premises equipment $(C P E)$ depending of trench length ,

$\operatorname{cost}_{C P}-$ price of customer premises equipment (Customer Premisis - $C P$ )

Cost function mainly consists of digging and equipment costs. To install new optical fibre one must to dig or to blow. Cost $\operatorname{cost}_{L}$ has two parts: cost of the fibres and cost of the trenching. The $C O$ contains OLTs which are installed on a dedicated chassis. Used OLT contains four OLT ports, each serving maximum of 64 ONUs (Optical Network Unit) at the customer. In the next section we will calculate cost function and compare GPON to P2P cost functions in Bosnia and Herzegovina.

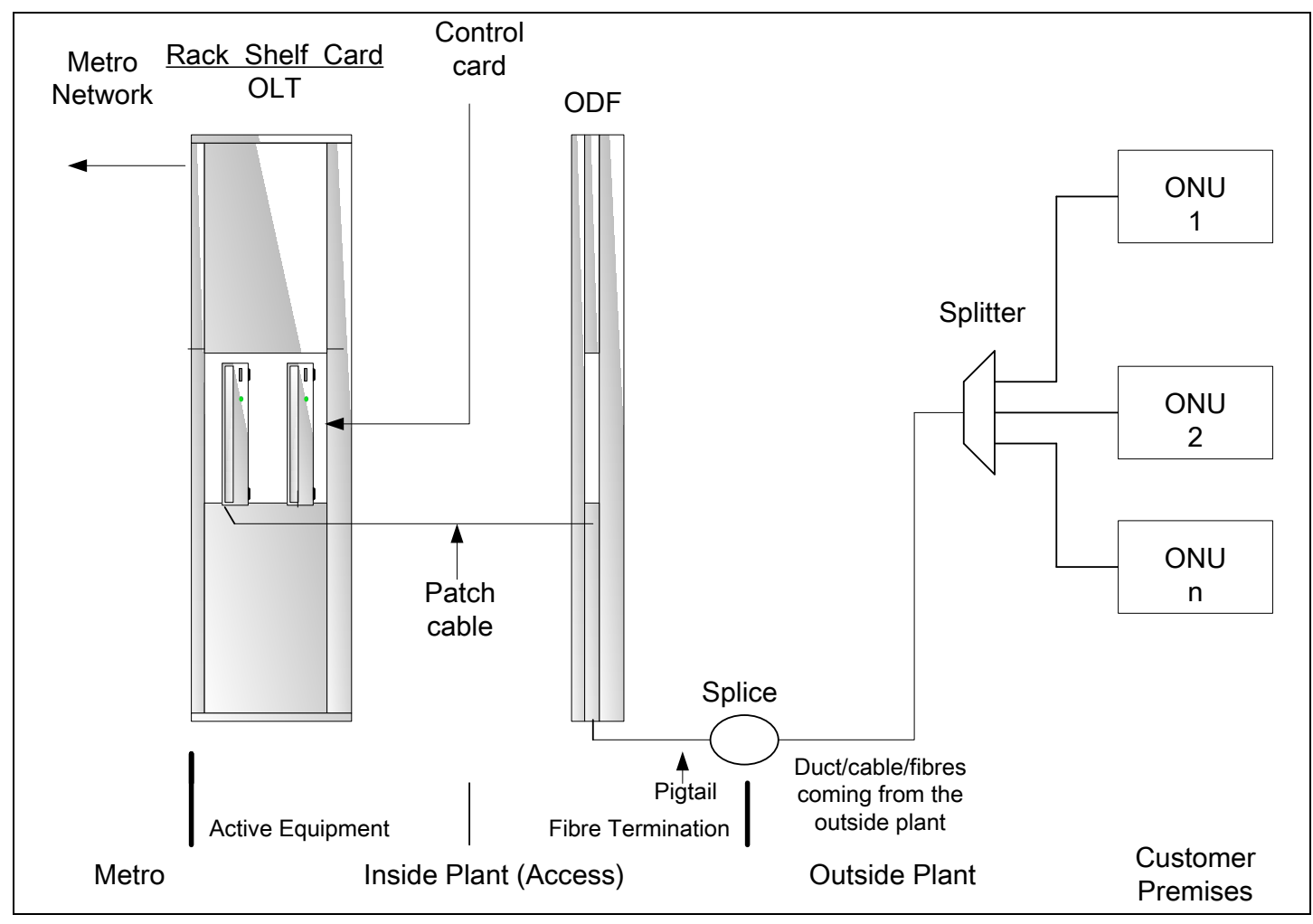

Figure 1. Optical network 


\section{Algorithm}

The analysis was made in MATLAB. Function $\operatorname{cost}_{L}$ is cost for the trench (fibre in duct and trench). $\operatorname{cost}_{C O}$ is equipment cost function. We define in general:

$$
\begin{gathered}
\operatorname{cost}_{\mathrm{L}}(\mathrm{t})=\mathrm{L}_{\text {trench }} \cdot \mathrm{C}^{\text {fibre }}(\mathrm{t}) \cdot \mathrm{N}(\mathrm{t})+\mathrm{L}_{\text {trench }} \cdot \mathrm{N}(\mathrm{t}) \cdot \mathrm{C}^{\text {trench }}(\mathrm{t}) \\
\operatorname{cost}_{C o}(\mathrm{t})=\frac{\operatorname{Crack}(t) \cdot N(t)}{f_{g 1}}+\frac{\operatorname{Cport}(t) \cdot N(t)}{f_{g 2}} \\
+\frac{\operatorname{Cshelf}(t) \cdot N(t)}{f g 3} \\
\operatorname{cost}_{\mathrm{CP}}(\mathrm{t})=\mathrm{C}^{\text {modem }}(\mathrm{t}) \cdot \mathrm{N}(\mathrm{t})
\end{gathered}
$$

and for $P 2 P$

$$
\begin{aligned}
& \sum_{t=1}^{\operatorname{cost}_{P 2 P}(t)} C^{\text {rack }}(t) \cdot \frac{N(t)}{f_{g 1}}+C^{\text {port }}(t) \frac{N(t)}{f_{g 2}}+C^{\text {shelf }}(t) \frac{N(t)}{f_{g 3}}+ \\
& +L_{\text {trench }} \cdot C^{\text {fibre }}(t) \cdot N(t)+ \\
& L_{\text {trench }} \cdot \mathrm{N}(\mathrm{t}) \cdot C^{\text {trench }}(\mathrm{t})+C^{\text {modem }}(t) \cdot N(t)
\end{aligned}
$$

and for P2MP

$$
\begin{gathered}
=\sum_{t=1}^{T} C^{\text {rack }}(t) \cdot \frac{N(t)}{f_{g 1}} C^{\text {post }}(t) \frac{N(t)}{f_{g 2}}+C^{\text {shelf }}(t) \frac{N(t)}{f_{g 3}}+ \\
+L_{\text {trench }} \cdot C^{\text {fibre }}(t) / 64+L_{\text {trench }} \cdot \mathrm{N}(\mathrm{t}) \cdot \mathrm{C}^{\text {trench }}(\mathrm{t})+ \\
+C^{\text {modem }}(t) \cdot N(t)
\end{gathered}
$$

$N(t)$ - number of subscribers

$f_{g 1}, f_{g 2}, f_{g 3}$ - granularity of the rack, card and shelf (Example:If we have 240 subscribers and line card has 24 port; we need 10 line cards)

$L_{\text {trench }}$ - average length of trench

$C^{\text {fibre }}$ - price of the fibre

$C^{\text {rack,port,shelf }}$ - price of the rack, port, shelf

$\mathrm{T}$ - time of implemetation

Assuming following input data we calculate the Capex for $P 2 P$ and $P 2 M P$ architecture:
The Bosnia \& Herzegovina has 200,000 households in urban area, 300,000 suburban and 450,000 rural households [22].

Average distance of the trench is $8 \mathrm{~m}$ in urban area, $20 \mathrm{~m}$ in suburban and $92 \mathrm{~m}$ in rural area, (data from BH Telecom).

The evolution of the network upgrades follows curve based on Gopertz model ( $a=6, b=0.4)$ [23].

Installations cost of network is $30 \%$.

Proposed take rate is $60 \%$.

We have set the splitting ratio at 1:64 with centralised splitter

We have set trench cost to $20 € / \mathrm{m}$ (price in $\mathrm{B} \& \mathrm{H}$ ).

Table 1. Cost of the Used $P 2 m p$ (Gpon) Equipment

\begin{tabular}{|c|c|c|}
\hline Component & Price $(€)$ & Number of customers \\
\hline OLT & 24,000 & 256 \\
\hline Chassis for OLT & 60,000 & 5,120 \\
\hline $1: 2$ splitter & 12 & 64 \\
\hline $1: 4$ splitter & 31 & 32 \\
\hline $1: 8$ splitter & 58 & 8 \\
\hline ONU & 150 & 1 \\
\hline Rack $(P 2 P)$ & 1,500 & 2,400 \\
\hline Shelf & 800 & 480 \\
\hline OLTcard $(P 2 P$ Ethernet $)$ & 5,000 & 24 \\
\hline ONU $($ P2P) & 130 & 1 \\
\hline
\end{tabular}

Fibre installation costs are shown in Table 2

Table 2. Fibre Installation Costs

\begin{tabular}{|c|c|c|c|c|c|c|}
\hline \multirow{2}{*}{$\begin{array}{c}\text { Installatio } \\
\text { n method }\end{array}$} & \multicolumn{3}{|c|}{ Cost $(€ / \mathrm{m})$} & \multicolumn{3}{c|}{ Share (\%) } \\
\cline { 2 - 7 } & Urban & $\begin{array}{c}\text { Sub } \\
\text { urban }\end{array}$ & Rural & Urban & $\begin{array}{c}\text { Sub } \\
\text { urban }\end{array}$ & Rural \\
\hline Digging & 20 & 20 & 15 & 80 & 75 & 70 \\
\hline Pulling & 2 & 2 & 2 & 10 & 5 & 0 \\
\hline Aerial & 5 & 5 & 5 & 10 & 20 & 30 \\
\hline
\end{tabular}

We have used the calculator shown in Fig. 2.

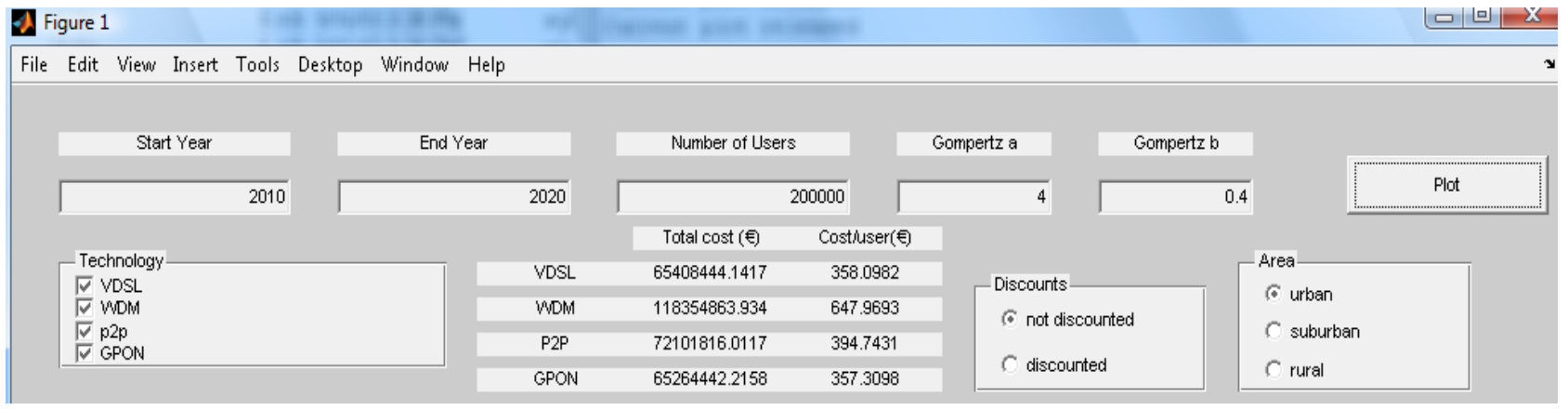

Figure 2. Cost calculator 


\section{Results}

Static cost analysis is based on the fixed input parameters as mentioned before. Business model has been developed to calculate and analyse costs and revenues of a B\&H future FTTH network and possibility to implement FTTH technology in our country.

We have calculated the total Capex costs for an FTTH rollout in Bosnia \& Herzegovina. Capex cost per customer is 333 EUR in urban area (Table 3). Currently, Capex per customer in cooper networks (only POTS and ISDN) is 300 EUR.

Fig. 3. depicts Capex cost per year and Figure 4 Total cost for urban, suburban and rural areas. Table 4 shows cost per subscriber for P2P and P2MP (GPON) technology.

Main revenues of the network are generated by the customer subscriptions. Table 4 shows the corresponding monthly fee (flat fee).

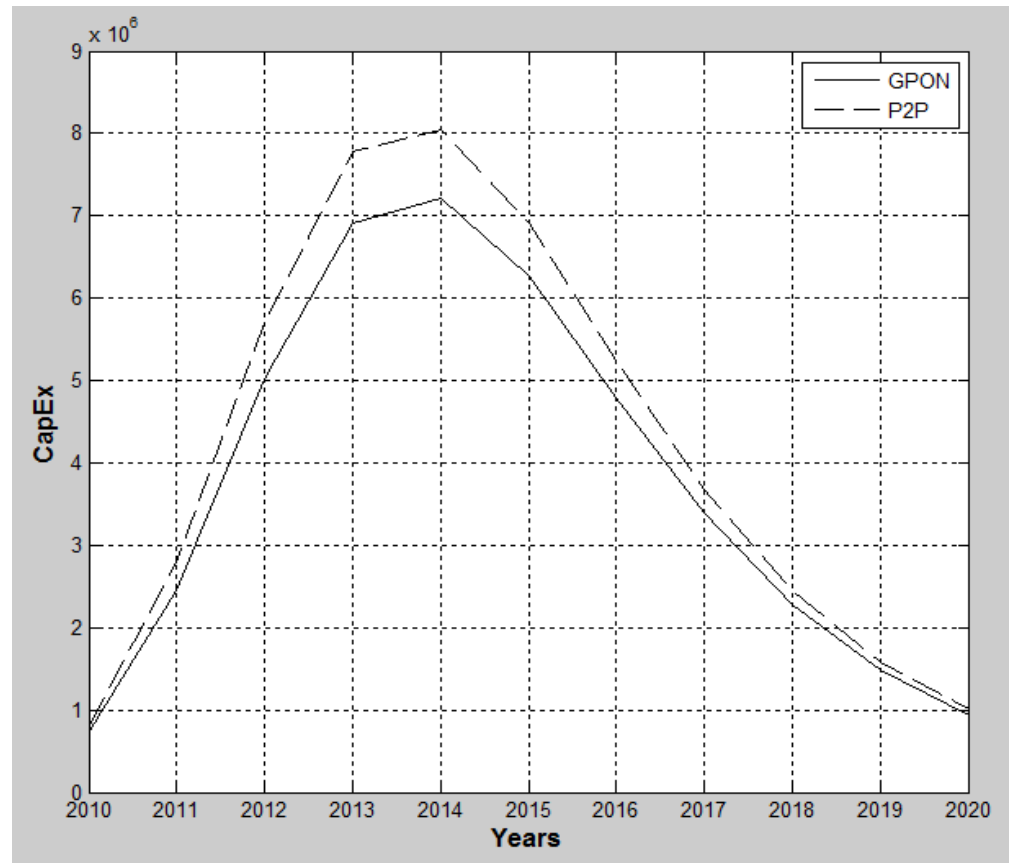

Figure 3. CapEx (GPON and P2P)

Table 3. Cost Per Subscriber

\begin{tabular}{|c|c|c|c|c|c|c|}
\hline \multirow{2}{*}{ Technology } & \multicolumn{3}{|c|}{ Cost (M€) } & \multicolumn{3}{c|}{ Cost/subscriber( $€)$} \\
\cline { 2 - 7 } & Urb. & Suburb. & Rur. & Urb. & Suburb. & Rur. \\
\hline P2MP(GPON) & 54.5 & 120 & 541 & 333 & 493 & 1.442 \\
\hline P2P & 59.2 & 128 & 530 & 362 & 522 & 1.472 \\
\hline
\end{tabular}

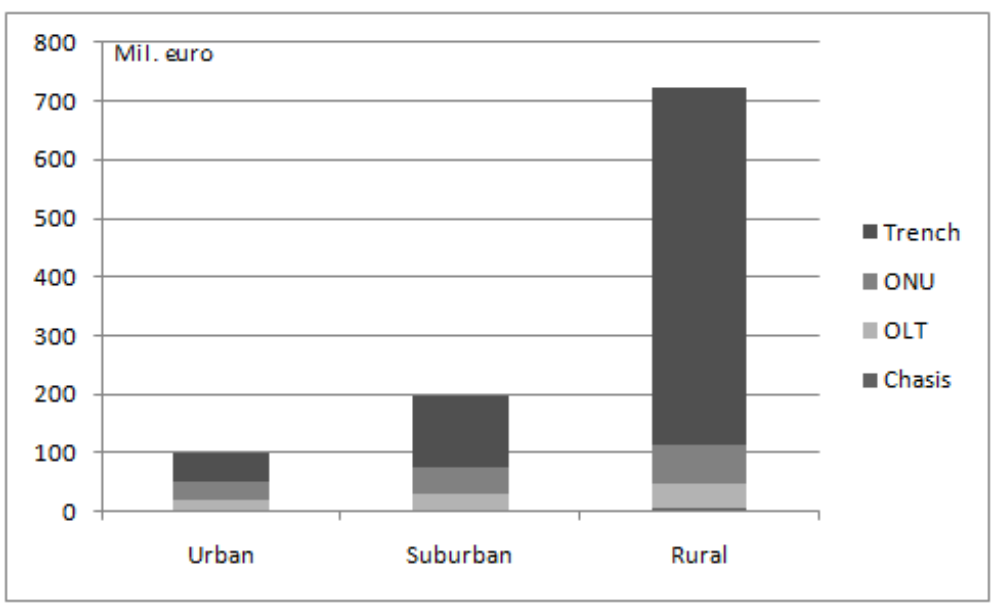

Figure 4. Total cost $(P 2 M P-G P O N)$ in urban, suburban and rural area 
Table 4. Monthly Tariffs

\begin{tabular}{|c|c|c|c|c|}
\hline \multirow{2}{*}{ Subscription } & \multicolumn{2}{|c|}{$\begin{array}{c}\text { Tariff } \\
\text { (EUR/month) }\end{array}$} & \multicolumn{2}{c|}{ Share (\%) } \\
\cline { 2 - 5 } & Residential & Business & Residential & Business \\
\hline Economical & 10 & 80 & 30 & 10 \\
\hline Standard & 20 & 120 & 60 & 60 \\
\hline Premium & 30 & 300 & 10 & 30 \\
\hline
\end{tabular}

As illustrated in Figure 5. FTTH rollout generates a positive $N P V$ and payback after 5 years.

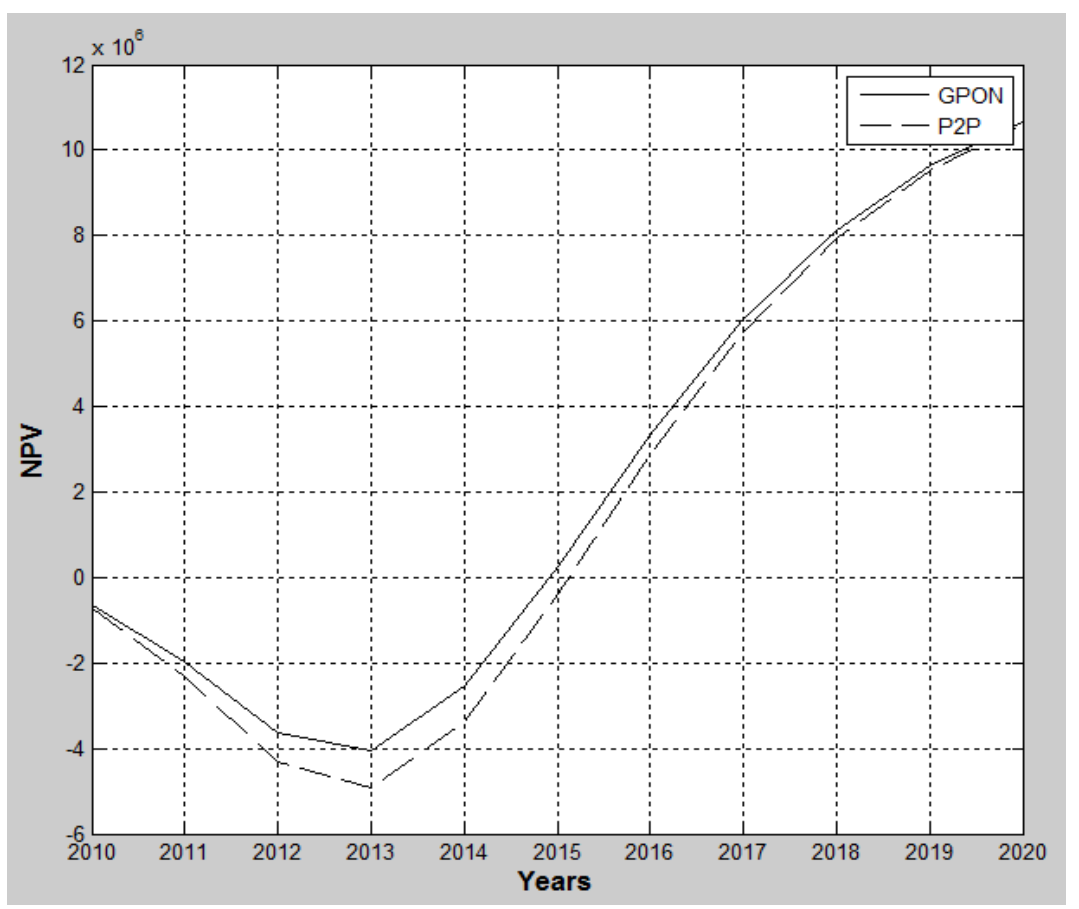

Figure 5. $N P V$ and payback period analysis (P2P and $\mathrm{P} 2 \mathrm{MP}$ urban) according to the rollout period

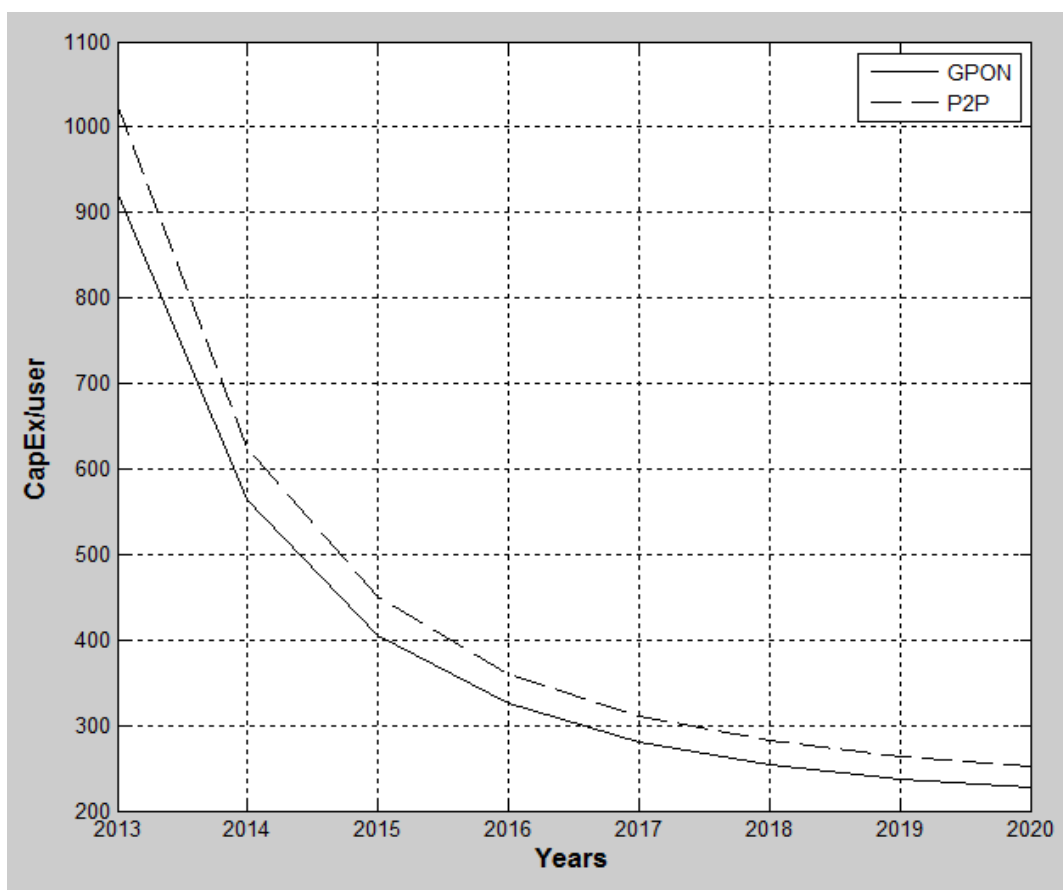

Figure 6. Influence of take rate on monthly fee 


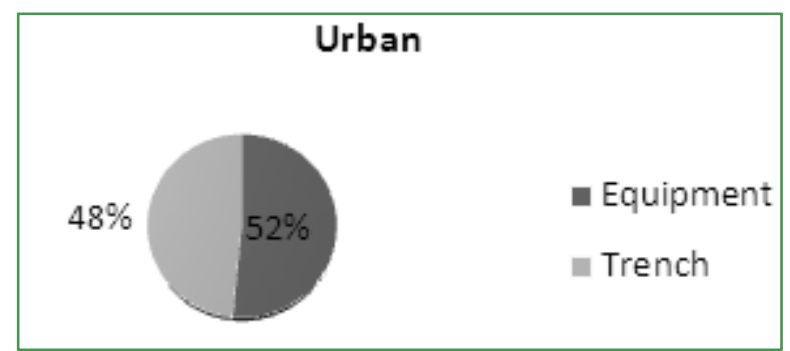

Figure 7. Division of the Capex costs at urban area

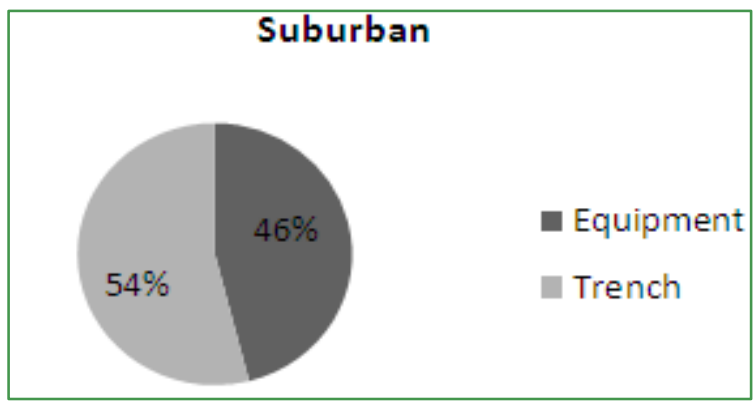

Figure 8. Division of the Capex costs at suburban area

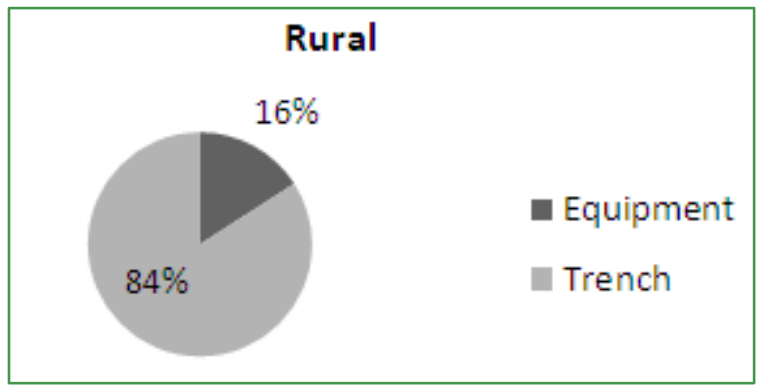

Figure 9. Division of the Capex costs at rural area

\section{Sensitivity Analysis}

When we need more information on the possible variations of outcome vs. variations on the input, we use sensitivity analysis.

In basic sensitivity analysis, we investigate the impact on the outcome of varying one input parameter at a time, keeping the other parameters fixed. The resulting sensitivity information is the variance of the outcome for the given variation of the input parameter. First, we calculate NP (Net Present Value) [22].

$$
N P V=\sum_{t=0}^{T} \frac{C F_{t}}{(1+r)^{t}}
$$

where:

$t$ - time of the cash flow,

$C F_{t}$ - cash flow at time $t$,

$T$ - total time period of the project and

$r$-discount rate (e.g. 10\%)

We are varying the price of $O N U$, line card and optic fibre for $\pm 5 \%, \pm 10 \%$ and $\pm 15 \%$ and obtained next results.

\section{Conclusions}

Most operators do not consider FTTH to be viable. They rather extend their existing infrastructure. When rolling out a new network, digging cost will play a decisive role, especially in rural areas. Important value is the Capex cost per home passed $(H P)$. This cost is given in Table 3 .

The results in Table 3 show us, the cost per customer is 333 EUR in urban area. Currently BH Telecom is paying 300 EUR per customer (only POTS and ISDN). Our analysis shows that FTTH network in B\&H is economically viable in urban area.

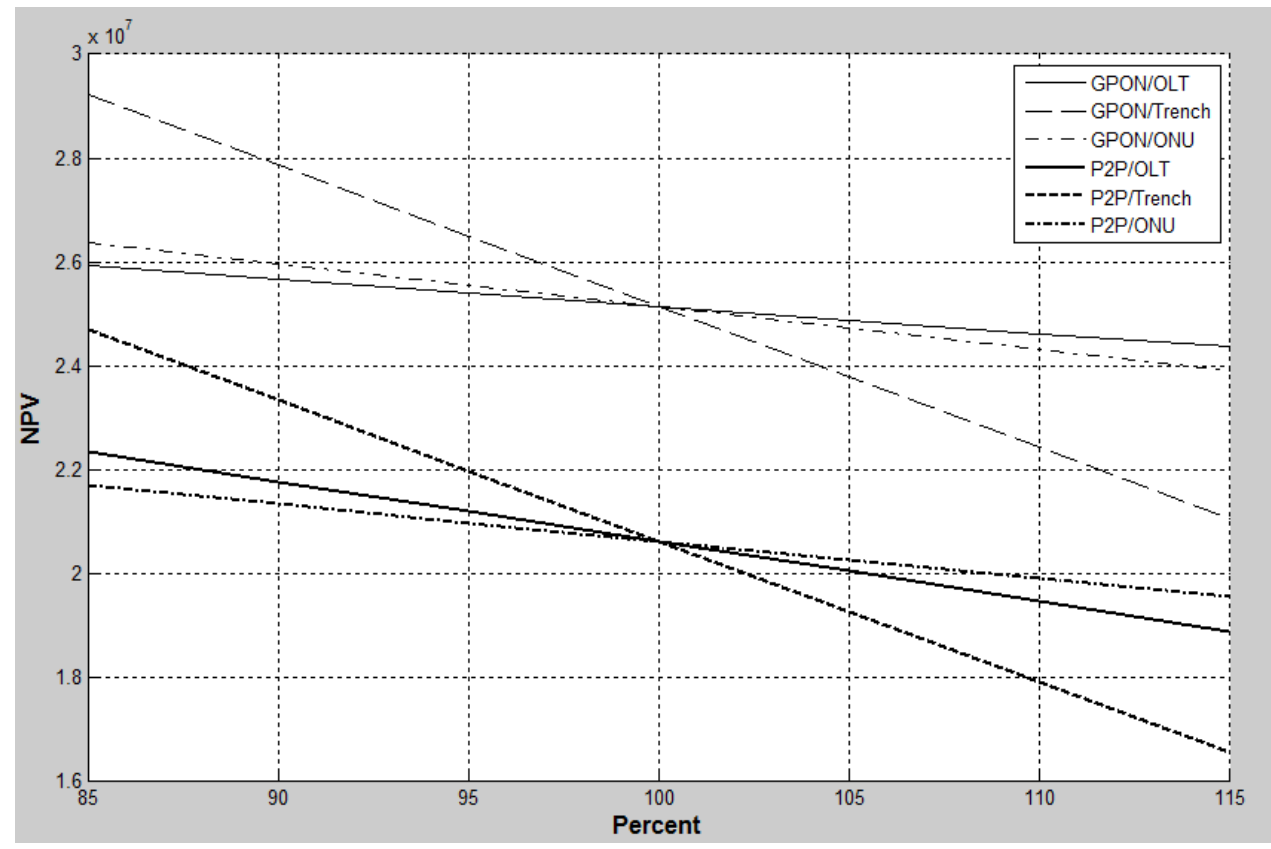

Figure 10. Sensitivity analysis for price variations of digging cost, OLT and ONU 
Reducing of digging cost can significantly improve FTTH rollout. Combining digging works with planned road works, using existing duct with micro-pipes are good alternative to limit the digging cost. The results in Fig. 10 show us, the $P 2 P$ technology is more sensitive than $P 2 M \mathrm{P}$, if we change percentage of price of digging cost, OLT and ONU.

The aim of this study was an analysis the feasibility of the FTTH rollout in Bosnia \& Herzegovina and comparing rollout scenarios in urban, suburban and rural areas. If the urban areas are considered, and if digging cost can be reduced, a feasible rollout is possible. These results are not valid only for the considered study in Bosnia \& Herzegovina, but they can also be extended to other future networks in other countries.

\section{REFERENCES}

[1] B. Lannoo, L. Verslegers, D. Colle, M. Pickavet, M. Gagnaire, and P. Demeester, "Analytical Model for the IPACT Dynamic Bandwidth Allocation Algorithm for EPONs", Journal of Optical Networking, vol. 6, pp. 677-688, June 2007.

[2] S. Verbrugge, K. Casier, B. Lannoo, J. Van Ooteghem, R. Meersman, D. Colle, and P. Demeester, "FTTH deployment and its impact on network maintenance and repair costs", International Conference on Transparent Optical Networks ( ICTON), 2008

[3] K. Casier, S. Verburgge, J. Van Ooteghem, D. Colle, R. Meersman, M. Pickavet, and P. Demeester, "Impact of sensitivity and iterative calculation on cost-based pricing", Proc.of CTTE 2007, $6^{\text {th }}$ Conference on Telecommunication Techno-Economics, Helsinki, Finland, Jun. 2007.

[4] ITU-T Recommendations, "G-series: Transmission systems and media, digital systems and networks" (http://www.itu.int/rec/T-REC-G/e).

[5] DSL Forum (http://www.dslforum.org/).

[6] J. M. Cioffi, S. Jagannathan, M. Mohseni, and G. Ginis, "CuPON: The Copper Alternative to PON $100 \mathrm{~Gb} / \mathrm{s}$ DSL Networks", IEEE Communications Magazine, vol. 45, pp. 132-139, June 2007.
[7] Point Topic: Global broadband statistics (http://www.point-topic.com)

[8] DOCSIS (http://www.docsis.org/).

[9] CableLabs (http://www.cablelabs.com/).

[10] P. E. Green, "Fiber-to-the-Home: The Next Big Broadband Thing", IEEE Communications Magazine, vol. 42, pp. 100-106, Sep. 2004.

[11] IEEE 802.3ah Ethernet in the First Mile Task Force (http://www.ieee802.org/3/ah/).

[12] IEEE 802.3av Task Force, 10Gb/s Ethernet Passive Optical Network,(http://www.ieee802.org/3/av/).

[13] ITU-T G.984.1, “Gigabit-capable Passive Optical Networks (GPON):General characteristics," March 2003.

[14] ITU-T G.984.2, "Gigabit-capable Passive Optical Networks(GPON):Physical Media Dependent (PMD) layer specification," March 2003.

[15] ITU-T G.984.3, "Gigabit-capable Passive Optical Networks (GPON): Transmission convergence layer specification," Feb. 2004.

[16] ITU-T G.984.4, “Gigabit-capable Passive Optical Networks (GPON): ONT management and control interface specification," June 2004.

[17] ITU-T G.984.5, "Enhancement band for gigabit capable optical access networks", Sep. 2007.

[18] WiMAXForum (http://www.wimaxforum.org/).

[19] K. Casier, S. Verbrugge, J. Van Ooteghem, D. Colle, R. Meersman, M. Pickavet, and P. Demeester, "Impact of sensitivity and iterative calculations on cost-based pricing", Proc. of CTTE 2007, 6th Conference on Telecommunication Techno-Economics, Helsinki, Finland, Jun. 2007.

[20] G. Kramer, B. Mukherjee, and G. Pesavento, "Interleaved Polling with Adaptive Cycle Time (IPACT): A Dynamic Bandwidth Distribution Scheme in an Optical Access Network", Photonic Network Communications, vol. 4, pp. 89-107, Jan. 2002.

[21] Department for a statistics, Federation B\&H Sarajevo.

[22] B. Lannoo, "Study of Access Communications Networks for Heterogeneous Environments, 20 